\title{
Dinâmica e evolução de sistemas familiares de produção leiteira em Uruará, frente de colonização da Amazônia brasileira
}

\author{
Nathalie Hostiou ${ }^{1}$ \\ Jonas Bastos da Veiga ${ }^{2}$ \\ Jean-François Tourrand ${ }^{3}$
}

Resumo: A propriedade agrícola é cada vez mais reconhecida como um objeto de estudo complexo. Isso se torna importante quando nela se intervém para fornecer um conselho de orientação ou uma ajuda à gestão, ou, num quadro mais amplo, no âmbito de um plano de desenvolvimento rural. Nos estabelecimentos leiteiros das frentes pioneiras da Amazônia, cuja diversidade de funcionamento é particularmente marcante, a modelagem da diversidade, graças à construção de tipologias, representa uma etapa importante para a organização do desenvolvimento agrícola. A partir do caso das explorações leiteiras no município de Uruará, na frente pioneira da Transamazônica, foram identificados cincos principais tipos de sistemas de produção de leite e trajetórias desses. A combinação dessas duas tipologias levou a caracterizar as principais dinâmicas possíveis dentro da diversidade dos sistemas leiteiros, representando as principais evoluções entre os tipos de propriedades. Os resultados salientam a importância de fatores socioeconômicos na implementação e desenvolvimento da atividade leiteira. Nesse contexto, as propostas formuladas devem favorecer a integração da produção leiteira, a sua permanência e a melhoria das condições de produção.

\footnotetext{
${ }^{1}$ Eng $^{\circ}$. Agr ${ }^{\circ}$, Ph D, pesquisadora do INRA, Equipe TSE. nhostiou@clermont.inra.fr

${ }^{2}$ Eng $^{\circ}$. Agr ${ }^{\circ}$, Ph D, pesquisador da Embrapa Amazônia Oriental. jonas@cpatu.embrapa.br

${ }^{3}$ Méd. Vet., Ph D, pesquisador do Convênio Embrapa-Cirad. tourrand@aol.com
} 
Palavras-chave: Sistemas Leiteiros, Diversidade, Dinâmica, Tipologia, Amazônia.

\section{Classificação JEL: Q010}

Abstract: The farm is each time more recognized as an object of complex study. This if becomes important when the farm is the object to supply an advice of orientation or an aid to the management, or the scope of a plan of agricultural development. For the dairy farms in agricultural borders of the Amazon, characterized by an important diversity of operation mode, the modeling of the diversity with the elaboration of typologies is an important stage for the organization of the agricultural development. From the case of dairy farms in Uruará municipio, situated on the Transamazonian frontier region, five main types of systems of milk production and theirs trajectories had been identified. Associating these two typologies, it was possible to identify the main dynamics within the diversity of the dairy systems, which represent principal evolutions between groups of farms. The results emphasize the importance of socioeconomics factors for the installation and the development of the dairy production. Inside this context, proposals can be formulated to promote the beginning of the dairy production, its stability and the improvement of the conditions of production.

Key words: Dairy Farms, Diversity, Dynamic, Typology, Amazon.

JEL Classification: Q010 Sustainable development

\section{Introdução}

A partir de 1960-1970, iniciou-se o processo de ocupação da Amazônia através da colonização agrícola, facilitada pela abertura das grandes rodovias. Apoiados pelos programas de colonização, milhares de pequenos produtores, oriundos de todas as regiões do Brasil, se instalaram em terras ao longo das estradas. Como conseqüência, o desflorestamento nas terras firmes da Amazônia se intensificou. Em 2003, já tinham sido abertos $652.908 \mathrm{~km}^{2}$, o que corresponde a mais de 16 \% da Amazônia Legal. Nos sistemas de produção familiar, o 
processo de introdução da pecuária passa a ser marcante a partir do inicio da década de $\underline{1990}$, em conseqüência de razões econômicas e sociais, dentre outras (IAI, 2001). Nas frentes de colonização agrícola, a produção leiteira, diversificação da pecuária de cria, contribui para a sustentabilidade da agricultura familiar por vários motivos, principalmente pela geração de renda significativa e regular ao longo do ano (Poccard-Chapuis et al. 2001; Machado, 2000). Mesmo com o aumento da produção nos últimos anos, a região Norte importa a maioria dos seus produtos lácteos, o que ressalta a importância socioeconômica do desenvolvimento da produção leiteira regional. Ao nível das propriedades, o problema principal que restringe a rentabilidade das explorações é a baixa produtividade das vacas, decorrente, principalmente, do inadequado manejo alimentar, reprodutivo e sanitário do rebanho (Tourrand et al. 1998).

Nas fronteiras agrícolas, os sistemas pecuários mistos (leite-carne) caracterizam-se pela diversidade e dinâmica que dependem de vários fatores, tais como origem geográfica dos colonos, condições socioeconômicas dos produtores na chegada à frente pioneira, motivações e razões da migração, projetos agrícolas e da família (Ferreira, 2001). No funcionamento dos estabelecimentos, a produção de leite parece pouco estável, mudando rapidamente em função de oportunidades e de eventos conjunturais (IAI, 2001). Os estabelecimentos leiteiros caracterizam-se por processos de construção e estruturação diversos e, por isso, apresentam diferentes níveis de evolução do sistema produtivo e dos fatores de produção. Isso salienta a importância de se compreender essa evolução para implementar ações de pesquisa e técnicas adaptadas a essas situações. A partir do exemplo das propriedades leiteiras do município de Uruará, na frente pioneira da Transamazônica, essa pesquisa tem por objetivo identificar os tipos de sistemas de produção de leite e as suas trajetórias, assim como caracterizar as suas principais dinâmicas. Esses resultados permitem se formular estratégias para apoiar o desenvolvimento sustentável de propriedades leiteiras nas fronteiras agrícolas da Amazônia brasileira. 
Dinâmica e evolução de sistemas familiares de produção leiteira em Uruará, frente de colonização da Amazônia brasileira

\section{Metodologia}

\section{1. Área de estudo}

O município de Uruará, ocupando uma área de $10.791 \mathrm{~km}^{2}$, situa-se no Estado do Pará na Amazônia Oriental Brasileira, na rodovia Transamazônica (BR-230), região de frente pioneira desde 1970. Tanto as terras da artéria principal como das estradas marginais, construídas perpendicularmente, foram divididas em lotes de 100 hectares. A população se concentra principalmente no meio rural (70\% dos 45.000 habitantes, segundo o IBGE, 2000). A agricultura de Uruará é desenvolvida principalmente por pequenos proprietários rurais (Veiga et al. 1996). A produção de leite se desenvolve com base numa cadeia produtiva local, de modo que a comercialização do leite é informal, sem nenhuma transformação (Poccard-Chapuis et al. 2001).

\subsection{Construção de tipologias de sistemas de produção leiteira}

Conhecer a diversidade das propriedades é cada vez mais reconhecido como essencial para melhorar a eficácia das intervenções junto aos agricultores. Para se entender essa diversidade, foram desenvolvidos métodos baseados na modelagem dos sistemas de produção agrícolas através de tipologias (Capillon, 1985). A construção de tipologias busca elaborar dispositivos de comparação pertinente das propriedades e, conseqüentemente, analisar, compreender, julgar os sistemas estudados e elaborar soluções adaptadas a cada realidade. Para evidenciar a diversidade dos sistemas leiteiros foram realizadas entrevistas com 30 produtores leiteiros do município. O questionário, priorizando o componente "produção leiteira", foca fatores de produção, uso da terra e infra-estrutura. Para analisar essas informações, foram consideradas 14 variáveis importantes na determinação e diferenciação dos sistemas de produção. Nelas foi realizada uma análise estatística multifatorial, associando uma análise dos componentes principais $(\mathrm{ACP})$ e uma classificação ascendente hierárquica (CAH), utilizando o programa Winstat.

Conforme Capillon (1993), a tipologia modela a diversidade das 
propriedades agrícolas em uma determinada data. Porém, a tipologia pode tomar uma dimensão dinâmica através da análise das trajetórias, ou seja, da identificação da história e da lógica de evolução das propriedades. A análise das trajetórias seguidas pelas propriedades visa caracterizar e entender as evoluções passadas que levaram aos tipos atuais de sistemas de produção. Para isso, foi aplicado um questionário sobre a evolução das estruturas de produção e das atividades produtivas. Essa entrevista retrospectiva com 25 produtores de leite resgata a história e o percurso do produtor, desde a sua chegada ao estabelecimento. A partir dessa base de dados, foi formalizada a trajetória individual de cada estabelecimento, o que levou a identificar oito critérios de diferenciação a serem utilizados na elaboração da tipologia das trajetórias. Foi elaborada a partir de análise estatística multivariada, através de uma análise fatorial dos componentes (AFC), usando o programa WebGridIII adaptado à análise de dados de tipo qualitativo (Girard et al. 2001).

Além do mais, é possível caracterizar as dinâmicas possíveis dentro da diversidade dos sistemas de produção. Uma dinâmica corresponde à ligação existente entre dois tipos de sistemas de produção, e representa as evoluções necessárias que leva à mudança do sistema. A caracterização das tendências evolutivas das propriedades (Perrot et al. 1995) é importante para acompanhar as transformações de estabelecimentos em regiões onde ocorrem rápidas mutações da agricultura. Para identificar as dinâmicas possíveis dentro da diversidade dos sistemas leiteiros - as principais evoluções entre os tipos de propriedades - foi realizado um cruzamento entre a tipologia dos sistemas de produção atuais e a tipologia das trajetórias (Monier, 1999). Para isso, foram determinados, para cada propriedade, os tipos de sistemas de produção pelos quais passaram ao longo da sua trajetória. Este trabalho foi conduzido a partir da análise das semelhanças entre a descrição, feita pelo produtor, de sistemas anteriores e os diferentes tipos atuais identificados. A seguir, foram determinadas as ligações existentes entre os tipos de estrutura de produção, descritas pelas mudanças de objetivos, e as evoluções (fatores de produção, atividades produtivas), assim como pelos tipos de trajetórias que levam à mudança de tipo. 


\section{Resultados e Discussão}

\subsection{Caracterização da diversidade dos sistemas de produção leiteiros}

A partir das analises estatísticas, foram identificados cinco tipos de sistemas leiteiros, cujas principais características são apresentadas na Tabela 1.

Tabela 1 - Principais características estruturais dos tipos de sistemas leiteiros

\begin{tabular}{|c|c|c|c|c|c|}
\hline Características & Tipo 1 & Tipo 2 & Tipo 3 & Tipo 4 & Tipo 5 \\
\hline \multicolumn{6}{|c|}{ Fatores de produção e nível de acumulação da propriedade } \\
\hline Idade do produtor & 33 & 41 & 54 & 43 & 55 \\
\hline Anos na produção leiteira & 3 & 7 & 11 & 6 & 4 \\
\hline Mão-de-obra total & 2,67 & 2 & 1,50 & 1,9 & 1,50 \\
\hline Efetivo bovino total & 303 & 55 & 125 & 91 & 29 \\
\hline Área da propriedade (ha) & 328 & 25 & 88 & 100 & 74 \\
\hline Área da pastagem (ha) & 170 & 20 & 73 & 66 & 32 \\
\hline Propriedades por produtor & 1 & 1 & 2 & 1 & 1 \\
\hline \multicolumn{6}{|c|}{ Nível de especialização da propriedade na pecuária } \\
\hline Efetivo total de vacas & 163 & 25 & 56 & 38 & 12 \\
\hline Efetivo de vacas leiteiras & 50 & 25 & 45 & 31 & 12 \\
\hline Efetivo de novilhos & 45 & 1 & 20 & 10 & 4 \\
\hline Produção leiteira anual (litros) & 34.200 & 27.250 & 23.300 & 19.000 & 6.160 \\
\hline $\begin{array}{l}\text { Área de lavoura perene } \\
\text { (\% da área cultivada) }\end{array}$ & 4 & 3 & 2 & 4 & 16 \\
\hline \multicolumn{6}{|c|}{ Produtividade leiteira e nível de especialização na atividade leiteira } \\
\hline Litros de leite/ha de pastagem/ano & 200 & 1.360 & 320 & 290 & 190 \\
\hline Carga animal anual (UA/ha/ano) ${ }^{4}$ & 1,37 & 1,50 & 1,20 & 0,80 & 0,77 \\
\hline
\end{tabular}

Fonte: Dados da pesquisa

O tipo 1 é representado pelas grandes propriedades pecuárias integrando a atividade leiteira à atividade cria-engorda (produção de bezerros e novilhos). Agrupa os maiores estabelecimentos leiteiros da amostra, com respeito aos fatores de produção, com uma área média de 330 ha, com 170 ha de pastagem e um rebanho total de 300 cabeças. A mão-

${ }^{1} 1$ vaca $=1$ Unidade Animal (U.A.) ; 1 reprodutor $=1,5$ U.A. ; 1 novilho(a) $=0,75$ U.A. ; 1 bezerro $=0,25$ U.A. 
de-obra é composta pela própria família e vaqueiros. Mesmo com uma importante produção (34.000 litros/ano), o leite não representa o produto principal que é constituída pela produção proporcionada por mais de 100 matrizes (bezerros e 45 novilhos para abate). A produtividade leiteira da pastagem é baixa, com uma média de 200 litros por hectare e por ano.

No tipo 2, são agrupadas as pequenas propriedades leiteiras mais intensivas, com uma produtividade de 1.360 litros de leite/hectare/ano e uma carga animal de 1,50 UA/hectare/ano. Todas as vacas (25) são produtoras de leiteira. O leite e os bezerros (vendidos logo após o desmame) são as únicas fontes de renda. Quase não resta reserva florestal: a propriedade está quase totalmente coberta por pastagem (20 ha dos 25). A força de trabalho é composta pelo produtor e um empregado. A atividade leiteira compõe a base do sistema de produção.

O tipo 3 é constituído por propriedades especializadas na pecuária leiteira, associando-a à cria e engorda. A maioria das matrizes é voltada à produção de leite (45 vacas das 56), sendo que as demais servem apenas para cria. Com um volume anual de 23.300 litros, o leite compõe uma atividade essencial no funcionamento dessas propriedades. São os estabelecimentos leiteiros mais antigos (11 anos). A área média das propriedades é de 88 hectares, com 73 hectares em pastagem. A pastagem é utilizada de forma relativamente intensiva, com 1,20 U.A/ha/ano e 320 litros de leite/ha/ano. Uma particularidade desse tipo é a engorda de novilhos-novilhas (20 cabeças), atividade associada à produção de leite e de bezerros. Além da família, a propriedade conta com a ajuda de um assalariado. Nesses estabelecimentos, o leite é uma atividade complementar à produção de bezerros e novilhos.

O tipo 4 representa as propriedades de dupla finalidade leite-carne, com rebanho de 91 rezes e uma área de pastagem de 66 hectares. A maioria das vacas serve à produção mista de leite e carne (31 vacas de um total de 38 matrizes). O volume de leite produzido é de 19.000 litros ao ano. A pastagem apresenta uma baixa produtividade com 0,80 UA/ ha/ano e 290 litros de leite/ha/ano. A pecuária é a atividade principal desenvolvida, sendo que as culturas, destinadas ao consumo familiar, ocupam apenas $4 \%$ da área.

No tipo 5, os sistemas de produção são diversificados, associando uma pequena produção leite-bezerros com culturas perenes. O leite re- 
presenta uma atividade complementar à produção de bezerros e dos cultivos. O rebanho é pequeno, composto de 29 rezes, com 12 vacas destinadas à produção mista leite-bezerros. $\mathrm{O}$ volume de leite produzido é baixo, com uma média de 6.160 litros no ano. A área de pastagem (32 ha) é pouca produtiva, com uma carga anual de 0,77 UA/ha/ano e uma produção de 190 litros de leite/ha/ano. Ao contrário dos outros tipos, a área dos cultivos representa $16 \%$ do total, o que salienta a importância das produções agrícolas no funcionamento desses estabelecimentos. Os produtores são os mais velhos da amostra, com idade média de 55 anos. A mão-de-obra é exclusivamente familiar composta pelo produtor e/ou um dos filhos (1,5 trabalhador).

\subsection{Origens dos sistemas leiteiros}

A partir das cinco trajetórias identificadas pela tipologia, foi possível caracterizar a história dos principais tipos de sistema leiteiro (Figura 1).

O tipo 1 é oriundo de uma trajetória denominada "atividade leiteira desenvolvida a partir de um rebanho de corte (cria e engorda), mantendo as duas produções” (TR1). O sistema de produção, após a instalação, se baseia na pecuária de cria e engorda junto às culturas perenes (café, pimenta e, às vezes, cacau). Um fator relevante da introdução da atividade leiteira é a tradição, sendo os produtores oriundos de famílias leiteiras. O potencial do gado é para corte, a partir do qual é desenvolvida a produção de leite. Aos poucos, o volume produzido foi aumentado com o crescimento do número de vacas. Além disso, um reprodutor de aptidão leiteira foi introduzido para melhorar o potencial produtivo das futuras matrizes. Os produtores mantêm dois rebanhos: um para a produção de leite e de bezerros e outro apenas para cria. O rebanho apresentou um crescimento bom e regular, o que justifica a formação de novas pastagens a partir da floresta primária, rápida e continuadamente. Além do mais, os produtores estruturam aos poucos as novas pastagens, construindo as cercas externas e as divisórias dos piquetes. O objetivo principal da atividade leiteira, nessa trajetória, é gerar uma renda complementar aproveitando a proximidade ao centro urbano.

Os estabelecimentos do tipo 2 seguiram uma trajetória visando aumentar a produção de leite através do aumento, tanto do rebanho como da produtividade (TR2). O leite se destacou como a atividade 
mais adequada à área disponível, sendo que os produtores compraram lotes menores às proximidades do centro urbano, com recursos próprios oriundos da venda de bovinos e de culturas perenes. O rebanho tem um padrão leiteiro devido à aquisição de reprodutores e matrizes especializados, comprados com financiamento ou recursos próprios. O seu crescimento foi médio e constante, às custas da própria reprodução, troca de bezerros por fêmeas e compra de animais com financiamento. A área de pastagem é expandida ao longo dos anos em função do crescimento do rebanho e da disponibilidade de capital.

As explorações do grupo 3 seguiram uma trajetória visando o desenvolvimento de uma atividade de engorda, junto à produção leite-carne (TR3). Os produtores dedicam-se à pecuária desde a chegada ao lote. A propriedade, a primeira adquirida ou conseguida após a saída do lote dos pais, e os primeiros animais foram comprados com capital próprio (venda de terra, herança, salário). Os produtores têm uma forte tradição na pecuária, com experiência adquirida junto ao pai ou numa propriedade especializada. Em alguns casos, o leite chegou a ser produzido logo em seguida à chegada no lote, em chácaras à proximidade da cidade. A base do rebanho resulta da compra de vacas e reprodutores de aptidão leiteira e, a seguir, através da seleção das próprias crias para a produção leiteira. Nos demais, a produção de bezerros foi a primeira e a única atividade realizada durante vários anos, e para aumentar a renda do gado de cria, os produtores decidiram vender o leite. A dupla atividade não levou a mudanças do rebanho, sendo que a orientação à produção de leite foi feita, aos poucos, trocando e selecionando as fêmeas e os reprodutores para essa atividade. Após uma fase de crescimento do rebanho, o efetivo foi mantido estável, assim como a quantidade de leite produzida. Os produtores chegaram a desenvolver uma atividade de engorda de novilhos na própria propriedade leiteira ou num outro lote da família, mais distante da cidade. A área de pastagem foi aumentada aos poucos, via abertura da mata e recuperação de áreas de pastagens degradadas. A formação da pastagem em toda a área da propriedade limita a sua expansão, e os produtores dedicam-se à melhoria da infraestrutura de pastejo (divisão de piquetes, corredores, açudes).

A trajetória dos estabelecimentos do grupo 4 (TR4) implica num rebanho de dupla finalidade, com o aumento do efetivo, sem especia- 
lização, para produção de leite. Os produtores chegaram à Amazônia junto com os pais, e uma vez adultos, instalaram-se na sua própria terra, com uma base do rebanho. Mesmo com preços mais elevados, eles compraram terras às proximidades do centro urbano, visando o bem da família (melhor acesso às facilidades da cidade). A produção leite-carne compõe a base do sistema, desde a chegada ao lote, ou foi adotada após uma orientação à atividade de cria. Os produtores são oriundos de famílias com bastante tradição na pecuária, experiência desenvolvida nas suas regiões de origem ou nos primeiros lotes explorados na Amazônia. Quando a produção de leite foi desenvolvida, a utilização de vacas de raças mistas não causou grandes modificações nas características genéticas das fêmeas. O crescimento contínuo e forte do efetivo efetuou-se essencialmente da própria reprodução do rebanho. A área de pastagem está em fase de formação, com rápida e continua expansão sobre a floresta. A construção da infra-estrutura da pastagem (cercas, corredores para manejo dos animais) é feita concomitantemente.

As propriedades pertencentes ao tipo 5 têm uma trajetória que integra um rebanho de dupla finalidade, visando a modificar um sistema de produção baseado em culturas perenes (TR5). Os lotes foram adquiridos no programa de colonização dirigido pelo INCRA ou após a venda da primeira terra. Esses produtores caracterizam-se pela pouca experiência na pecuária, a maioria deles era constituída de meeiros em propriedades de café, no Sul do país ou operários na cidade. Nos primeiros anos, o sistema de produção baseava-se nas culturas anuais destinadas ao auto-consumo e às vezes ao mercado. Com o aumento do capital e a obtenção de financiamentos, foram introduzidas culturas perenes. Possuíam apenas algumas rezes compradas com os recursos provenientes da venda de produtos agrícolas, com o objetivo de produzir leite para a família. Com um sistema funcionando à base de culturas, o rebanho quase não cresceu, sendo o descarte vendido para as despesas da família e da propriedade. Portanto, em seguida, o sistema enfrentou crises na lavoura, por falta de mão-de-obra devido à saída dos filhos do lote, doenças nos cultivos ou queda dos preços dos produtos. Por isso, a pecuária tornou-se mais importante no funcionamento da propriedade. Para aumentar o rebanho sem grandes investimentos, os produtores criavam gado de meia e alugavam pastos para 
outros pecuaristas. A compra de animais através de financiamentos mudou a estratégia e o comportamento dos produtores. Com um maior número de vacas, mesmo com taxa de crescimento baixa, devido à venda regular de rezes, o volume de leite ordenhado chegou a ultrapassar as necessidades de consumo da família, permitindo comercializar o excedente. Em alguns estabelecimentos, a pastagem é formada na área de floresta, com um crescimento lento e irregular, conforme crescimento do rebanho e do capital. Em outros, os produtores dedicam-se à recuperação de pastagens já formadas.

\subsection{Tendências evolutivas dos sistemas leiteiros}

O cruzamento entre a tipologia dos sistemas de produção e a das trajetórias permitiu se identificar as possíveis tendências dos sistemas leiteiros (Figura 1).

Não foram identificadas ligações entre as propriedades leiteiras pertencendo ao tipo $1 \mathrm{com}$ as demais. Essa particularidade se explica, em parte, pelas condições disponíveis na instalação das propriedades, permitindo que os produtores adquirissem uma grande quantidade de terra, por serem mais capitalizados. Porém, uma evolução possível seria continuar aumentando o rebanho para corte até a estabilização da área de pastagem, com o fim da reserva florestal ou o alcance de uma área mínima de floresta. O projeto de aumentar o rebanho poderia implicar na compra de outras terras no município para implementar a atividade de engorda, mantendo a produção de leite e a cria de bezerros na propriedade próxima à cidade. Também o rebanho leiteiro continuaria aumentando para elevar a quantidade de leite produzido. Além do mais, uma maior orientação para a produção leiteira poderia ser adotada incorporando reprodutores de melhor genética. A quantidade de leite produzida vai depender da capacidade de comercialização.

O tipo 2 pode caminhar para o tipo 3 através da dinâmica de "elevar a renda da pecuária com a diversificação da produção bovina”. O produtor toma essa decisão diversificando as suas atividades, desenvolvendo a atividade de cria-engorda. A atividade leiteira fica relativamente intensiva na propriedade próxima à cidade, enquanto numa outra terra mais distante do centro urbano maneja as vacas de cria e os novilhos e 
novilhas. Os fatores decisivos dessa transformação são: o fim da reserva florestal dificultando a implantação de novas pastagens, as dificuldades de comercializar maior quantidade de leite, a demanda de tempo do produtor para explorar a atividade leiteira e a necessidade de aumentar a renda para realizar os projetos da família (construção de uma casa na cidade, instalação dos filhos numa terra).

Propriedades pertencendo ao tipo 3 podem passar para o tipo 5 devido às dificuldades encontradas na pecuária leite-carne, com a dinâmica de "diversificar o sistema de produção". Problemas enfrentados, tais como a redução de capital e falta de mão-de-obra após a saída dos filhos, afetaram a atividade pecuária e contribuem para redirecionar o sistema de produção, com a introdução de culturas perenes para tentar melhorar a renda. No contexto de Uruará, não foi identificada outra evolução para os estabelecimentos do grupo 3 que passam a ser uma forma estabilizada.

Propriedades do tipo 4 podem evoluir para o tipo 3 com uma dinâmica de "aumentar a renda da pecuária com a diversificação da produção bovina”. Após uma fase de crescimento do efetivo bovino e da produção bovina, a atividade leiteira estabiliza-se tanto no efetivo de vacas como no volume ordenhado. Esse processo ocorre por várias razões: sobrecarga de trabalho para manejar o sistema (e. g. ordenha manual e venda do leite na cidade), dificuldade de comercializar o leite (mercado local pouco desenvolvido), estabilização da área de pastagem, devido o fim da reserva florestal. A estabilização da produção leiteira leva a integrar a atividade recria-engorda dos novilhos, na própria propriedade leiteira ou em outra terra própria, no município. O aumento do rebanho indica a estratégia desses pecuaristas de melhorar a renda. $\mathrm{O}$ tipo 4 pode passar para o grupo 5 com uma dinâmica de diversificar o sistema de produção, através da introdução de culturas. Essa transformação pode ocorrer quando boa parte do rebanho é usada para atender o bem-estar da família (construção de residência na cidade) e investir em atividades não-agrícolas. Com esses projetos levados a cabo pela família, o rebanho é fortemente reduzido e, conseqüentemente, a sua produção. A lavoura perene é introduzida como novo investimento na propriedade.

Estabelecimentos do tipo 5 podem evoluir o tipo 4, após a especialização na pecuária leite-carne. $\mathrm{O}$ incremento da pecuária resulta de um 
financiamento para aquisição de algumas vacas e de problemas nos cultivos (doenças, queda dos preços), levando o produtor a diminuir a ênfase na agricultura, chegando a desativá-la.

Figura 1 - Trajetórias e tendências evolutivas dos sistemas leiteiros no município de Uruará

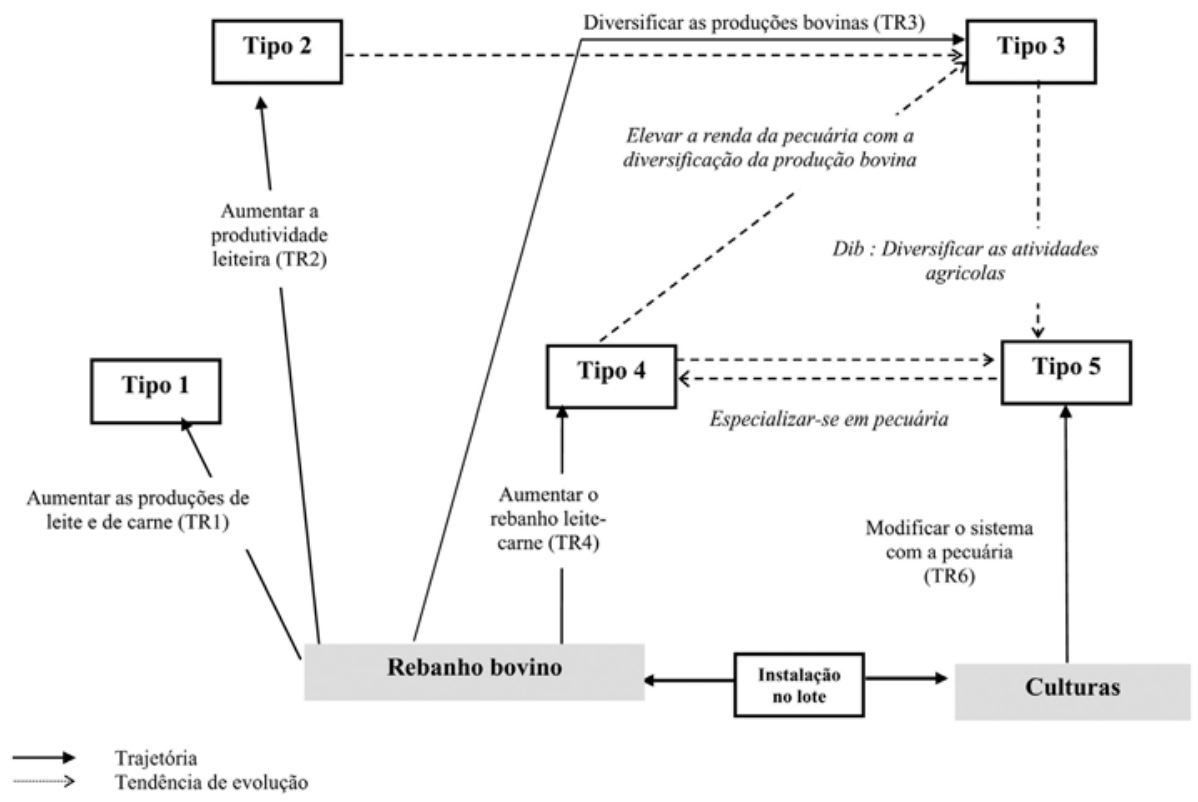

\subsection{Propostas para apoiar a sustentabilidade dos sistemas de produção leiteiro na Amazônia}

Observa-se que todos os sistemas de produção leiteiros são desenvolvidos por estabelecimentos que enfatizam ou priorizam a criação de gado em relação às outras explorações. As evoluções das propriedades mostram pouca tendência à especialização na produção leiteira, à intensificação e melhoria da produtividade leiteira. A lógica do sistema leite-carne encontra-se fortemente inseridas nas estratégias, trajetórias e projetos dos produtores familiares, devido a vários fatores. No município de Uruará, a organização da comercialização local é pouco desenvolvida, com baixa capacidade de escoamento da produção e com forte concorrência entre os produtores. O rebanho bovino, mesmo constituindo uma atividade 
produtiva primordial, mantém sua função de acumulação, utilizada para desenvolver os projetos familiares (compra de terras) ou enfrentar situações difíceis (doença na família). Por isso, muitas vezes, os projetos para a pecuária são pouco definidos, o que se expressa na intenção dos produtores de "ter o máximo de rezes". Essa estratégia prioriza a expansão da área de pastagem e do rebanho, em vez da intensificação do sistema de produção, visando o aumento da produtividade. A atividade leiteira se transforma ao longo das trajetórias das propriedades familiares. O leite não representa um projeto de produção, a longo prazo, para todos os produtores. Pode constituir uma fase na trajetória das propriedades, cujos projetos tentam incrementar o rebanho bovino, melhorar a qualidade de vida das famílias, educar os filhos e implementar novas atividades agrícolas ou não agrícolas. Os resultados salientam a importância de fatores socioeconômicos na implementação e desenvolvimento da atividade leiteira, sendo os mais importantes: a disponibilidade em mão-de-obra (idade do produtor, presença e permanência dos filhos na propriedade e o envolvimento deles na atividade), o capital disponível, tanto para o desenvolvimento da atividade propriamente dita (compra de rezes, formação de pastagens) como para enfrentar as crises (doenças na família, etc.). Além disso, outros fatores essenciais são: a obtenção de crédito (importante para produtores pouco capitalizados iniciarem ou desenvolverem a atividade leiteira) e os próprios projetos para a família (construção de residência na cidade, educação dos filhos).

Nesse contexto, as propostas de intervenção devem favorecer a integração e a permanência da produção leiteira no funcionamento desses sistemas, e a melhoria das condições de produção. Políticas públicas devem ser formuladas para apoiar o desenvolvimento de cooperativas e associações de produtores leiteiros, assim como políticas fiscais e de crédito para favorecer a emergência de laticínios, para absorver a produção. Também é essencial melhorar a infra-estrutura das bacias leiteiras (estradas, rede de coleta de leite, energia, etc.). A diversidade das propriedades leiteiras, ao nível da estrutura de produção e da evolução, confirma a necessidade de formular pacotes tecnológicos diferenciados e adaptados. São necessários estudos focados nos principais tipos de sistema de produção leiteira, procurando, mais especificamente, caracterizar as práticas implementadas 
pelos produtores (quais são as praticas?) e os fatores determinantes (quais são as razões dessas práticas?). Essa compreensão pode valorizar e facilitar a difusão das recomendações técnicas desenvolvidas, assim como melhorar as ações de pesquisa-desenvolvimento ou as políticas públicas a serem formuladas. A divulgação das recomendações técnicas num universo complexo e heterogêneo de produtores, força uma reflexão sobre a natureza do apoio técnico para fornecer aos agricultores familiares. As ações que parecem essenciais a desenvolver são: estimular a discussão de grupo entre produtores e realizar dias-de-campo para mostrar práticas de sucesso. Além do mais, as próprias organizações de produtores podem exercer um papel fundamental na extensão rural, no que diz respeito ao manejo e sanidade do rebanho, acesso aos insumos e equipamentos, financiamentos e créditos e capacitação dos produtores.

\section{Conclusões}

Os resultados dessa pesquisa salientam a diversidade de situações atrás do conceito de "explorações leiteiras" nas frentes pioneiras da Amazônia brasileira. Isso ressalta a necessidade de se reformular as ações direcionadas a esses sistemas de produção familiar, para levar em conta as peculiaridades, tanto ao nível da estrutura de produção como da própria capacidade dos produtores de adotar as recomendações e técnicas. Isso poderia permitir melhores condições para desenvolver a produção leiteira e melhorar a sustentabilidade técnico-econômica dos estabelecimentos familiares envolvidos.

\section{Referências bibliográficas}

CAPILLON, A. Typologie des exploitations agricoles, contribution à l'étude régionale des problèmes techniques. 1993. 48p. Tese (Doutorado) - Institut National Agronomique de Paris-Grignon, Paris - França.

CAPILLON, A. Connaître la diversité des exploitations : un préalable pour la recherche des références techniques régionales. Agriscope, v.6, p. 31-40, 1985. 
FERREIRA, L. A. Le rôle de l'élevage bovin dans la viabilité agro-écologique et socio-économique des systèmes d'exploitations agricoles familiaux en Amazonie orientale brésilienne - le cas d’Uruará. 2001. 187p. Tese (Doutorado) - Institut National Agronomique de Paris Grignon, Paris - França.

GIRARD, N. et al. Categorising combinations of farmers' land use practices: an approach based on examples of sheep farms in the south of France. Agronomie, v.21, p. 435-459, 2001.

IAI. Projeto Cattle ranching, Land-Use and Deforestation in Brasil, Peru and Ecuador - Relatórios Pará, Maranhão e Acre. Gainesville, USA : University of Florida, 2001. 40 p.

IBGE. Censo demógrafico 2000. Resultados do Universo. População residente, por situação do domicílio e sexo, segundo as Grandes Regiões e as Unidades da Federação - Brasil - Grandes Regiões. Disponível em http://www.ibge.gov.br. Acesso em julho de 2004.

PERROT, C.; PIERRET, P.; LANDAIS, E. L'analyse des trajectoires des exploitations agricoles. Une méthode pour actualiser les modèles typologiques et étudier l'évolution de l'agriculture locale. Economie Rurale, n. 228, p. 35-47, 1995.

POCCARD-CHAPUIS, R. et al. A cadeia produtiva do leite: uma alternativa para consolidar a agricultura familiar nas frentes pioneiras da Amazônia Oriental? In IV ENCONTRO DA SOCIEDADE BRASILEIRA DE SISTEMAS DE PRODUÇÃO. BELÉM, 2001. Anais... Belém: Sociedade Brasileira de Sistemas de Produção, 2001. p.1 - 16.

MACHADO, R.C. Estudo dos sistemas de criação da agricultura familiar através da abordagem das práticas : o caso de bovinos leiteiros da agricultura familiar na microrregião de Marabá-PA. 2000. 181p. Dissertação (Mestrado) - Universidade Federal do Pará, Belém - PA.

MONIER 1999 Fonctionnement des élevages bovins, diversité et trajectoires dans deux cantons des Hautes-Alpes. 1999. 105p. Dissertação (M. Sc.) - ISARA, Lyon - França.

TOURRAND, J. F. et al. Produção leiteira em área de fronteira agrícola da Amazônia: o caso do município de Uruará, PA na Transamazônica. 
In: HOMMA, A. K. O. Amazônia : meio ambiente e desenvolvimento agrícola. Brasília : Embrapa-SPI/Belém : Embrapa -CPATU, 1998. p. 345-386.

VEIGA, J. B. da; TOURRAND, J. F.; QUANZ, D. A pecuária na fronteira agrícola da Amazônia: o caso do município de Uruará, Pa, na Transamazônica. Belém : Embrapa-CPATU. 1996. 61 p. (Documentos).

Recebido em novembro de 2004 e revisto em abril de 2006 